\title{
Self-reflection in cognitive behavioural therapy and supervision
}

\author{
Jan Prasko ${ }^{\mathrm{a}, \mathrm{e}}$, Petr Mozny ${ }^{\mathrm{b}, \mathrm{e}}$, Miroslav Novotny ${ }^{\mathrm{c}, \mathrm{e}}$, Milos Slepecky ${ }^{\mathrm{d}, \mathrm{e}}$, Jana Vyskocilova ${ }^{\mathrm{e}}$
}

\begin{abstract}
Objective. Supervision is a basic part of training and ongoing education in cognitive behavioural therapy. Self-reflection is an important part of supervision. The conscious understanding of one's own emotions, feelings, thoughts, and attitudes at the time of their occurrence, and the ability to continuously follow and recognize them are among the most important abilities of both therapists and supervisors. The objective of this article is to review aspects related to supervision in cognitive behavioural therapy and self-reflection in the literature.

Methods. This is a narrative review. A literature review was performed using the PubMed, SciVerse Scopus, and Web of Science databases; additional references were found through bibliography reviews of relevant articles published prior to July 2011. The databases were searched for articles containing the following keywords: cognitive behavioural therapy, self-reflection, therapeutic relationship, training, supervision, transference, and countertransference. The review also includes information from monographs referred to by other reviews.
\end{abstract}

Results. We discuss conceptual aspects related to supervision and the role of self-reflection. Self-reflection in therapy is a continuous process which is essential for the establishment of a therapeutic relationship, the professional growth of the therapist, and the ongoing development of therapeutic skills. Recognizing one's own emotions is a basic skill from which other skills necessary for both therapy and emotional self-control stem. Therapists who are skilled in understanding their inner emotions during their encounters with clients are better at making decisions, distinguishing their needs from their clients' needs, understanding transference and countertransference, and considering an optimal response at any time during a session. They know how to handle their feelings so that these correspond with the situation and their response is in the client's best interest. The ability to self-reflect increases the ability to perceive other people's inner emotions, kindles altruism, and increases attunement to subtle signals indicating what others need or want. Self-reflection may be practised by the therapists themselves using traditional cognitive behavioural therapy techniques, or it may be learned in the course of supervision. If therapists are unable to recognize their own thoughts and feelings, or the effects of their attitudes in a therapeutic situation, then they are helpless against these thoughts and feelings, which may control the therapist's behaviour to the disadvantage of the client and therapist alike.

Conclusion. Training and supervision focused on self-reflection are beneficial to both supervisees and their clients. The more experienced the supervisor is, the more self-reflection used in therapy and supervision.

Key words: supervision, cognitive behavioural therapy, self-reflection, transference, countertransference

Received: August 1, 2011; Accepted with revision: February 24, 2012; Available online: May 25, 2012

http://dx.doi.org/10.5507/bp.2012.027

${ }^{a}$ Department of Psychiatry, Faculty of Medicine and Dentistry, Palacky University Olomouc and University Hospital Olomouc, Czech Republic ${ }^{b}$ Mental Hospital Kromeriz

'Psychiatric Centre Jesenik

${ }^{d}$ ABC Centre, Liptovsky Mikulas, Slovak Republic

${ }^{e}$ Odyssea, International Institute of CBT

Corresponding author: Jan Prasko, e-mail: prasko@fnol.cz

\section{INTRODUCTION}

Conscious understanding of one's own emotions, feelings, thoughts, and attitudes at the time of their occurrence, and the ability to continuously follow and recognize them are among the most important abilities of therapists and supervisors. Boud et al. ${ }^{1}$ defined self-reflection as intellectual and affective activities in which individuals engage to explore their experiences in order to reach a new understanding and appreciation. Socrates's rule to "know thyself" is likely to be related to this essential prerequisite for lifelong wisdom - a constant awareness of one's own feelings and an openness to them. Selfreflection may also be characterized as non-reactive and non-judgemental attention to our inner states ${ }^{2}$. Such at- tention takes in whatever passes through awareness as an interested yet unreactive witness. Self-reflection is not attention that gets carried away by emotions, overreacting and amplifying what is perceived. Rather it is a neutral mode that maintains self-reflectiveness even amidst turbulent emotions. To refer to an awareness of the thought process and of one's own emotions, the terms metacognition $^{3}$ and metamood, respectively, are used. In this text, both will be referred to as self-reflection or self-awareness, since in most cases cognitive and emotional reactions are simultaneous and both occur at the same time during selfreflection, like two sides of the same coin.

Self-reflection in therapy has been described as a cyclic process in which the therapist critically assesses emotional and cognitive experiences, observes behavioural 
reactions, uses an inner dialogue and generalization to achieve insight, and changes the original attitudes and convictions concerning a therapeutic (or supervisory) situation $^{4-6}$. In self-reflective awareness, the mind witnesses and explores all experiences, including emotional and physical reactions ${ }^{7,8}$.

\section{METHOD}

This is a narrative review. A literature review was performed using the PubMed, SciVerse Scopus, and Web of Science databases; additional references were found through bibliography reviews of relevant articles. The search included papers indexed by the web-based electronic databases mentioned above published prior to July 2011. Databases were searched for articles containing the following keywords: cognitive behavioural therapy, selfreflection, therapeutic relationship, training, supervision, transference, and countertransference. The search was performed by repeated use of the words in different combinations with no language or time limitations. The articles were collected and sorted by relevance, and key articles listed in the reference lists were also searched. The review also includes information from monographs referred to by other reviews. Thus, the article is a review with conclusions concerned with self-reflection in cognitive behavioural therapy and supervision.

\section{THE SIGNIFICANCE OF SELF-REFLECTION}

Self-reflection plays an important role in establishing a therapeutic relationship ${ }^{9-11}$. Self-reflection in therapy is a continuous process. Realizing one's own inner experiences is an essential skill, from which other skills, knowledge, and attitudes necessary for therapy may stem. These include the recognition of one's role as a therapist, acknowledgement of transference and countertransference, emotional self-control, and continuous development of therapeutic competencies ${ }^{12,13}$.

In his Declarative-Procedural-Reflective (DPR) model, Bennett-Levy ${ }^{14}$ provided a useful model for conceptualizing therapist skill development. The model identifies three information processing systems ${ }^{14,15}$ :

1) The declarative system is a knowledge system founded on an intellectual understanding of theoretical models and their practical consequences ${ }^{16}$. When applied to self-reflection, it is the knowledge of what self-reflection and its significance are, how it may be trained, etc. Although such knowledge is fundamental for other systems, it is just a theory that cannot provide good therapy practice without practical experiences.

2) The procedural system is a storehouse of skills, attitudes, and behaviours in action. It involves practical competence, skills, and professional artistry. The system is supplied through training and practical experience with clients.

3) The reflective system is crucial for ongoing skill development ${ }^{17}$. Its role increases mainly when the acquired declarative knowledge and procedural skills are insufficient because the current situation is complicated, the client is resistant to previous approaches, or transference and countertransference occur. The capacity for self-reflection differentiates the average therapist from the expert therapist ${ }^{18}$. This system is mainly built by supervision and regular self-reflection.

Therapists who are skilled in understanding their inner emotions during their encounters with clients are better at making decisions, distinguishing their needs from their clients' needs, understanding transference and countertransference, and considering an optimal response at any time during a session ${ }^{19,20}$. They know how to handle their feelings so that these correspond with the situation and their response is in the client's best interest. Self-reflecting therapists continuously recognize their own cognitive and emotional functioning, and their emotional expressions are cultivated ${ }^{13}$. Knowing one's own reactions becomes a basis for independence, awareness of limitations, and mood control. Self-reflection is particularly important when working with difficult clients. Hoffart et al. ${ }^{21}$ examined whether therapists' emotional reactions to their agoraphobic clients mediate the effect of personality disorders in patients and interpersonal problem behaviours on the outcome of treatment. The severity of personality disorder was significantly related to the therapists' feelings of insecurity. A higher level of therapist insecurity was related to poorer treatment outcomes.

Jennings and Skovholt ${ }^{22}$ studied the personal characteristics of master therapists to show that reflectiveness plays a crucial role in their therapeutic functioning. These master therapists appear to have emotional receptivity defined as being reflective, non-defensive, and open to even negative feedback. These experts typically desire to learn and understand the ambiguous nature of their life experiences and use self-reflection both in their therapeutic practice and in their personal lives to better understand themselves and others.

The ability to self-reflect also increases the ability to perceive other people's inner emotions, kindles altruism, and increases attunement to subtle signals indicating what others need or want ${ }^{2,23}$. Developing self-reflection is particularly important, as studies have shown that as many as $60 \%$ of clinical psychologists work with their clients even at times when they feel unwell and their work is not effective ${ }^{24}$. Training attention onto one's own emotions and the ability to self-reflect may increase the ability to recognize personal discomfort, preventing any negative impact on clients ${ }^{17,25}$. Training self-reflection in therapy is extremely important for beginner therapists, since this skill aids in developing critical thinking and ethical decision-making. From a transcultural perspective, the therapist's self-reflection is an integral component of the process of establishing a relationship, sharing power, and encouraging the client's opinion. For culturally sensitive practice, it is important to realize how the cultural, ethnic, or racial identities of the client, supervisor, and supervisee influence the therapeutic and supervisory relationships ${ }^{26}$. 
Reflectiveness is frequently used as a synonym for self-reflection. During teacher trainer programmes, it is considered an essential element for developing the ability to think critically ${ }^{27-29}$. It is also applied in medical ${ }^{30}$ and health care ${ }^{31}$ education. A study of nearly 200 medical students showed that continuous reflection is one of the key components of their training, enabling an increase in their ability to learn more skills during their courses ${ }^{30}$. Similarly, reflectiveness has been taught during the training of professionals caring for mentally disabled patients, and for their supervision ${ }^{32,33}$.

In summary, the ability to self-reflect improves both procedural experience in the therapeutic process and the clinicians' ability to continually use their own emotions to better understand the therapeutic relationship ${ }^{34,35}$. Such ongoing self-reflection is similar to non-judgemental awareness as applied in mindfulness techniques ${ }^{36}$.

\section{DEVELOPMENT OF SELF-REFLECTION}

The general ability to self-reflect increases in the course of the therapeutic training itself, and the ability to self-reflect during therapy increases in the course of supervision $^{37,38}$. Self-reflection may be practised by the therapist using traditional cognitive behavioural therapy techniques or may be learned in the course of supervision ${ }^{39}$. When practising self-reflection, a vicious circle may be used to map one's own reactions to the patient ${ }^{13}$.

One option is to record automatic thoughts regularly after sessions, when therapists have enough time to consider what was happening and what they actually want, as well as why they react emotionally and behave in a particular manner. Another possibility is to use the downward arrow technique to analyse the therapist's own schemata for a better understanding of the attitudes that give rise to particular thoughts, emotions, and behaviour ${ }^{13}$.

It is also possible to make notes about one's thoughts during therapy sessions or when reviewing recordings of one's sessions with the patient ${ }^{40}$. Initially, supervisees are concerned about recording, since they feel insecure about their skills and fear negative evaluation from others as well as from themselves once they see the recording $^{41}$ (Hawkins and Shohet 2000). Supervision is aimed at providing the supervisees with a view of themselves that may produce anxiety at first. In the course of supervision, however, supervisees usually get used to the process and ignore the camera after several recordings are made. If supervision is safe, encouraging, and respectful, recording causes no problems after a short period of time ${ }^{13}$.

\section{PROBLEMS WITH SELF-REFLECTION}

If therapists are unable to recognize their own thoughts and feelings, or the effects of their attitudes in a therapeutic situation, then they are helpless against these thoughts and feelings, which may control the therapist's behaviour to the disadvantage of the client or even the therapist ${ }^{42}$. Therapists who are often driven by their emotions are unable to escape them. They often do not realize their feelings or cognitive reactions, and if they do it happens only after they act in a particular manner ${ }^{43}$. They are controlled by their moods, often act in a countertransference manner, and feel helpless in a therapeutic situation ${ }^{44}$.

Some people have problems with self-reflection. They hate thinking about themselves, and have problems recording what they think and what is happening in them emotionally. This often results from mental avoidance. Deeper self-reflection may bring thoughts and feelings

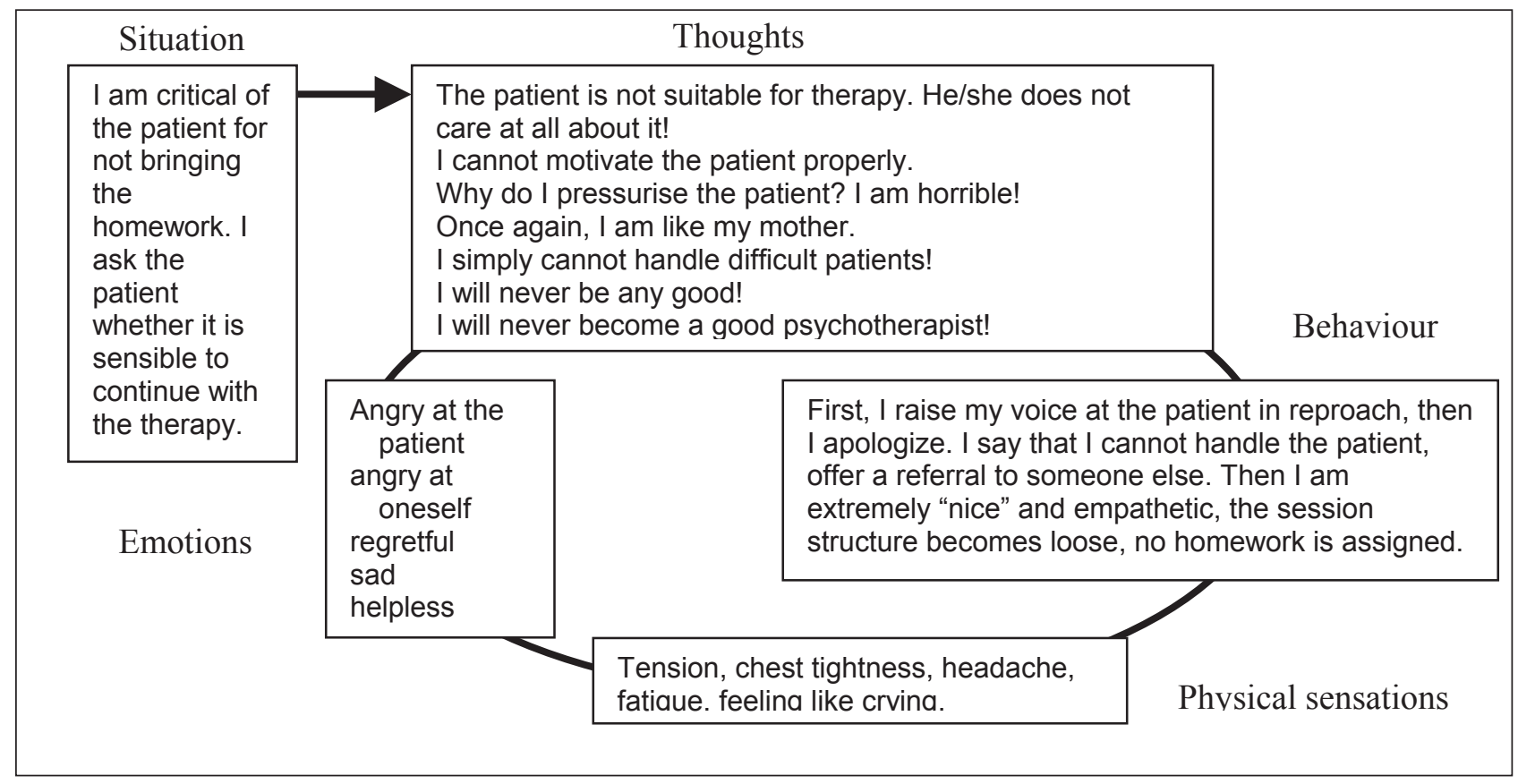

Fig. 1. A vicious circle of reaction to the patient during a therapy session. 
Table 1. Dysfunctional thought record - a therapeutic situation.

\begin{tabular}{|c|c|c|c|c|c|c|c|}
\hline Situation & $\begin{array}{l}\text { Automatic } \\
\text { thoughts: } \\
\text { I believe } 0-100 \%\end{array}$ & $\begin{array}{l}\text { Emotions: } \\
\text { Intensity 0-100\% }\end{array}$ & Facts for & Facts against & $\begin{array}{l}\text { Alternative } \\
\text { thought: } \\
\text { I believe } 0-100 \%\end{array}$ & $\begin{array}{l}\text { Emotions: } \\
\text { Intensity 0-100\% }\end{array}$ & $\begin{array}{l}\text { Action: } \\
\text { What now } \\
\text { What next time }\end{array}$ \\
\hline $\begin{array}{l}\text { I am bored and } \\
\text { yawning as the } \\
\text { patient uses the } \\
\text { same excuse } \\
\text { again and again. }\end{array}$ & $\begin{array}{l}\text { The patient } \\
\text { keeps saying the } \\
\text { same things! } \\
\text { It goes nowhere! } \\
\text { The patient does } \\
\text { not want to solve } \\
\text { anything! } \\
\text { The patient feels } \\
\text { good about this! }\end{array}$ & $\begin{array}{l}\text { Boredom } 70 \% \\
\text { Disgust } 80 \% \\
\text { Anger } 60 \% \\
\text { Contempt } 50 \%\end{array}$ & $\begin{array}{l}\text { The patient } \\
\text { did not do the } \\
\text { homework for } \\
\text { the third time. } \\
\text { The patient } \\
\text { repeatedly skips } \\
\text { sessions. } \\
\text { The patient did } \\
\text { fewer exposures } \\
\text { than we had } \\
\text { planned. }\end{array}$ & $\begin{array}{l}\text { The patient } \\
\text { keeps talking } \\
\text { about job dis- } \\
\text { missal; this is a } \\
\text { new problem. } \\
\text { The patient has } \\
\text { already done } \\
\text { many things and } \\
\text { improved a lot. } \\
\text { Now the patient } \\
\text { is overwhelmed } \\
\text { by being dis- } \\
\text { missed. } \\
\text { The patient did } \\
\text { fewer exposures } \\
\text { but still quite a }\end{array}$ & $\begin{array}{l}\text { The patient talks } \\
\text { about what is } \\
\text { most stressful } \\
\text { and what cannot } \\
\text { be managed. } \\
\text { Now the patient } \\
\text { is disappointed } \\
\text { that despite } \\
\text { much effort to } \\
\text { fight phobia, } \\
\text { there is new } \\
\text { stress when look- } \\
\text { ing for a job. } \\
\text { The patient does } \\
\text { not feel good in } \\
\text { this. }\end{array}$ & $\begin{array}{l}\text { Boredom 0\% } \\
\text { Disgust 30\% } \\
\text { Anger 20\% } \\
\text { Contempt } 0 \%\end{array}$ & $\begin{array}{l}\text { Now we will deal } \\
\text { with the most } \\
\text { serious problem. } \\
\text { During the next } \\
\text { sessions, I will } \\
\text { tackle both the } \\
\text { agoraphobia and } \\
\text { the job problem. }\end{array}$ \\
\hline
\end{tabular}

The downward arrow - identifying schemata about oneself

What does this mean about me?

I cannot treat the patient!

What is so bad about this for me?

Core schema: I am an incompetent therapist!

What would have to be done to make me feel competent?

To be competent, therapy with any patient must be perfect!
The downward arrow - identifying schemata about others

What does this mean about the patient?

The patient does that on purpose!

What is so bad about this?

The patients do those things to me on purpose!

What would have to be done to make a difference?

All patients should try hard to help me! that the person prefers not to have. For example, they might find that they are angry at others, or feel helpless, sad, or anxious. Such people are told by their cognitive and emotional schemata that they should not have such thoughts and feelings, and they have to drive them away, since these feelings represent weakness or unacceptability for others ${ }^{45}$. The same is true for therapists in training. However, blocks in self-reflection prevent understanding of countertransference phenomena and may limit the ability to establish a good therapeutic relationship, since the therapist is not aware of his or her own share in $\mathrm{it}^{44}$.

\section{SELF-REFLECTION AND SUPERVISION}

To a great extent, the therapist learns self-reflection during the supervision process. Thus, the therapist's attitudes and behaviour may be better utilized for the client's benefit. During training and supervision, self-reflection is continuously improved. Therapists who often use selfreflection in their work gradually increase their ability to self-reflect. Self-reflection is an important component of the growth of supervisees' clinical skills ${ }^{46}$. Therefore, it is important that supervisors strengthen the ability to self-reflect in supervisees. Unfortunately, it is more frequent that supervisors automatically turn their attention to the technical components of therapy and try to assess them, neglecting supervisee self-reflection. However, if insufficient attention is paid to supervisee self-reflection during supervision, the supervisee may fall into the trap of misunderstanding the client, and the therapy fails ${ }^{47}$. All supervisees, irrespective of how they are trained, may benefit from more attention paid to self-reflection ${ }^{20}$.

Feelings of insecurity and dissonance can make the clinician insecure. These feelings are influenced by the supervisor's and supervisee's personalities as well as by the supervision environment. In the process of supervision, self-reflection is learned during a dialogue between the supervisor and supervisee as they make a combined effort to understand the supervisee's emotional reactions in a particular therapeutic situation or relationship, based on how the supervisee understands the situation ${ }^{48,49}$. Selfreflection may result in a new understanding of the situation and a new reaction to be used in clinical practice. Simply, the supervisor and supervisee aim at a better understanding of how the supervisee thinks, feels, and behaves in interactions with the client, and then integrate this understanding into the therapeutic process during the sessions to come.

In a quantitative study of more than 100 mental health professionals at five stages in their career, Skovholt and Ronnestad $^{50}$ found that the introduction of training of continuous professional reflection may be a crucial factor for gradual professional maturation. Moreover, practitio- 
ners who introduced reflective attitudes into their clinical practice were able to create a supportive and open professional environment and often discussed their practice with their colleagues. In contrast, those who did not use self-reflection often showed insufficient and fragmented professional development.

Recordings of supervision sessions or colleague observations of supervision sessions may be important for self-reflection ${ }^{51}$. Feedback from watching recordings may show very clearly how the supervisor uses self-reflection. Supervisors may avoid critical self-reflection by asking the supervisees more and more questions or by responding with rather general or theoretical answers to questions. Sometimes, this is referred to as "game playing". Supervisors may avoid disclosing their own vulnerability or try to decrease their level of anxiety and insecurity by avoiding discussions about sensitive issues ${ }^{52}$. Supervisors may also avoid self-reflection, especially when they are oversensitive or, conversely, insensitive to criticism, afraid to show vulnerability, doubtful about supervision skills, and afraid to admit their ignorance or uncertainty about anything ${ }^{53,54}$. The fact that a supervisor avoids critical reflection may be documented by an emphasis on theory rather than discussion of personal or professional experiences $^{55}$. Self-reflection in supervisors may be strengthened by methods similar to self-reflection training for therapists, such as records of vicious circles and automatic thoughts or elaboration of cognitive schemata related to countertransference.

So far, very little attention has been paid to which strategies should be used to increase reflective attitudes in trainees and supervisees. Before supervision is even initiated, supervisors should reflect on their own attitudes to the supervisee and clarify to themselves how they perceive the new relationship and what emotions and feelings it evokes. This self-reflection process also involves attention to the cultural backgrounds of all participants - supervi- sor, therapist, and client. If it is beneficial for therapy, the supervisor may serve as a model for the therapist in how to reflect one's own deeper attitudes. At the beginning of supervision, supervisees tend to be tense, anxious, and insecure about their therapeutic role. However, they are highly motivated to do their best ${ }^{41}$. New trainees may fear supervisors' opinions of their work, criticism, comparisons with other supervisees, etc. Initially, supervision is typically characterized by a certain dependence on the supervisor. However, this may be reduced by self-disclosure, gradually creating a cooperative community of two partners. Through their own self-disclosure, supervisors usually inspire supervisees to be less afraid to self-disclose. The following extract describes self-reflection at the beginning of clinical supervision of a novice therapist undergoing cognitive behavioural training.

Olga is a 28 year old psychiatrist who comes from a farming family in a small village in Slovakia. She is the oldest daughter, and took care of her two younger brothers throughout her childhood. Olga's mother, an efficient, assiduous, and active woman, has always dominated the family. These traits were inherited by Olga, who worked hard academically and graduated from medical school. Her family is very proud of her. One year after completing her studies, she moved to the Czech Republic to start a career in clinical practice, get married, and enter CBT training.

One of Olga's patients is a 24 year old named Aleš. $\mathrm{He}$ is of Romani ancestry, and grew up in a large and very poor family. As a child, he often starved, wore ill-fitting and worn clothing, and was beaten by his older siblings. The family was dominated by the father, an alcoholic who was frequently unemployed. The mother was submissive and devoted, caring for her six children as well as she could. She only occasionally stood up to the father, for which she was beaten. Aleš also worked hard academically, and graduated from a technical university. He does not

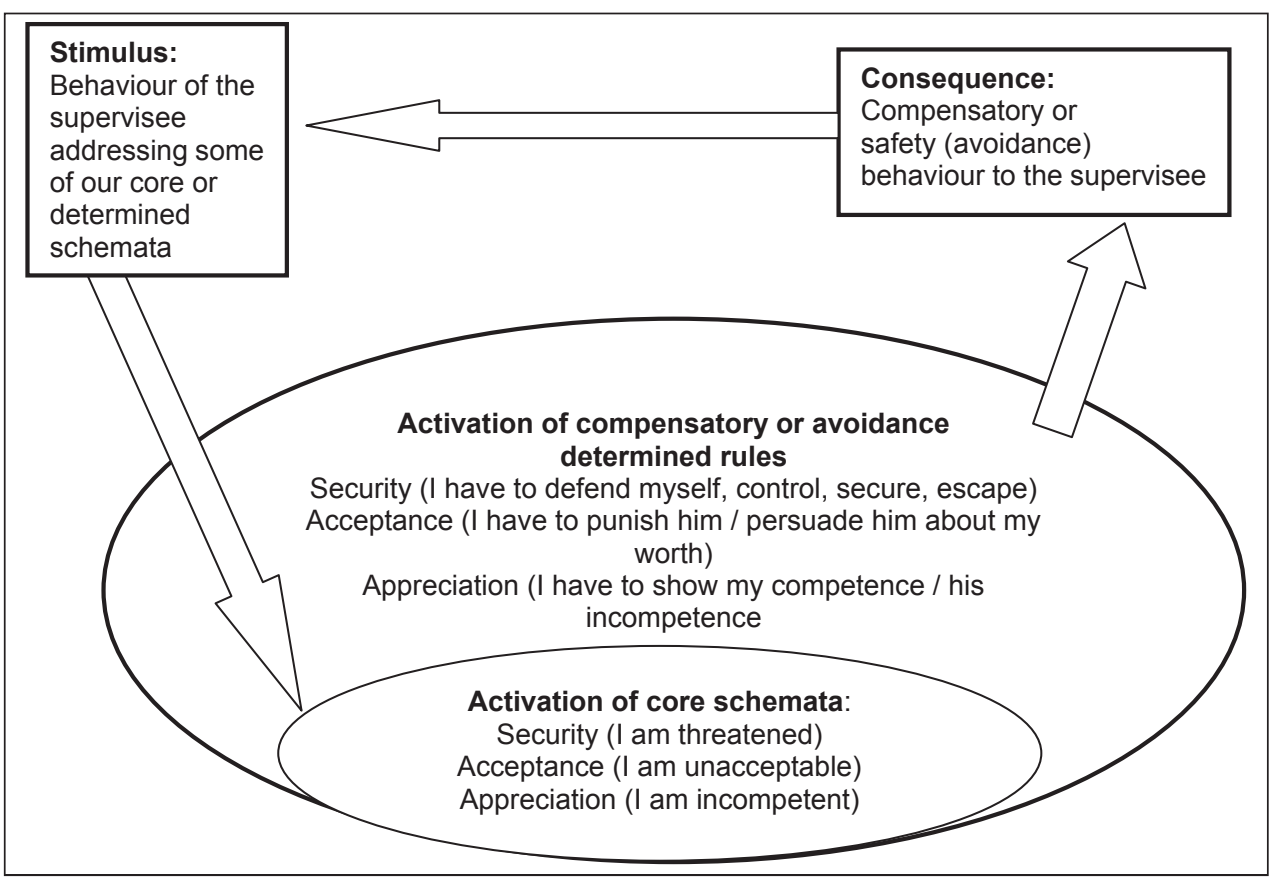

Fig. 2. A chart of countertransference in supervision ${ }^{42}$ 
have a partner. He became estranged from the Romani community, but he does not feel he is good enough for a white girlfriend. For four years, Aleš has suffered from frequent aggressive obsessions as part of an obsessivecompulsive disorder.

Olga's supervisor is Roman, a 35 year old clinical psychologist from Prague, who grew up in comfort as the only child in an intellectual family of generations of university graduates. His parents always competed with each other to see who was right or more competent, who would have the last word, etc. Despite constant arguments, they stayed together and basically got on well. Roman got his degree easily, with little effort. He never worked hard academically, but instead spent time on hobbies and with friends in Prague pubs. Roman is currently single. His previous partner left him for another man about three months ago, after a long relationship.

Olga and Roman work in different wards of the same facility. They seem attracted to each other. Once a week for four months, Roman has supervised Olga's therapy of Aleš. Roman is aware that Olga has only begun her psychotherapy training and clinical practice. He realizes that he, Olga, and the patient come from rather different environments, affecting their basic attitudes, needs, coping mechanisms, therapy goals, ability to self-disclose, and interactions. Moreover, each of them is currently in a different life situation, which may also affect both supervisory and therapeutic attitudes, as well as the patient's attitudes. Roman observes that Olga is very attractive, and sees that this may influence both his supervision and Aleš's relationship in therapy. To avoid false preconceptions and to understand Olga, and Aleš in the background, as much as possible, as well as to conceptualize Aleš's problems and the supervision of the therapeutic approaches used, Roman has put much emphasis on Olga's self-reflection and on the guided discovery of her own attitudes towards Aleš and herself from the very beginning. As all the participants have different cultural and psychosocial backgrounds, Roman is persuaded that self-reflection will be important for both Olga and himself, as it produces an open basis to build on in further supervision and possibly also in therapy.

During the first supervision session, Roman and Olga discussed and agreed on a supervision contract. They openly discussed conditions and limits, emphasizing the need for open feedback on both sides and agreeing to be honest under all circumstances and to eliminate any "game-playing" should it occur. Roman used selfdisclosure as an opportunity to normalize self-disclosure and personal reflection in the supervisory relationship by being an example. Roman said that although he was attracted to Olga, he would do his best not to let this interfere with the supervision work. Olga admitted that Roman was also attractive to her, but that she had never thought of flirting because she had a satisfactory relationship with her husband whom she loved. However, she was concerned about Roman's intelligence and sophistication, and feared appearing stupid because she was not as well versed. She admired him both as a therapist and supervi- sor, which could prevent her from disclosing potential problems. Bilateral self-disclosure helped to alleviate Olga's feeling of vulnerability. Roman also said that this supervision was a personal challenge for him, since he himself had to deal with the fact that he admired Olga for another reason: as a person who had worked hard academically. Since his school years, he had been prejudiced against people who try hard, and had considered them boring. But he realized that the attitude that "smart people do not have to try hard, only dull people try hard" was wrong and immature, protecting him from the fact that he had never been determined enough to try hard. Roman told Olga that he admired her for how hard she had worked in her life and for what she had accomplished. His grasp of culture actually was not his achievement, but simply the result of having been born to a family in which this was considered normal. What was not considered normal, on the other hand, were hard work and strong will, which were normal things for Olga. The contract encouraged Olga to self-reflect and included a request for discussing personal experiences in both therapy and supervision. Olga informed Roman that she had only had limited therapeutic experience, particularly in terms of working with people suffering from obsessive-compulsive disorder.

Roman realized that if his supervision was to help both Olga and Aleš, cultural and social differences should be included. Therefore he asked Olga about her attitude towards Romani people. She said that she had no problems with Aleš, whom she considered very intelligent and whom she admired for having worked hard academically. However, during her childhood in Slovakia, she had many Romani schoolmates whom she disliked. They were often dirty, wore tattered clothes, and had lice. As an adult, she thinks that she has no prejudices, as she now understands that Romani people did not choose their fate, had a very complicated history, and are under pressure to adapt to the majority. However, she is a bit mistrustful of them, fearing they may rob her. She has no such feelings with Aleš. Roman admitted to have similar mixed feelings about Romani people. Rationally, he is persuaded that they are people like him; he does not think he is more valuable, and he also realizes that the maladaptive behaviour of some of them stems from the history of enforced coexistence with the majority. On the other hand, he must admit to a prejudice, mostly in connection with their criminal behaviour, lack of hygiene, and cunning. As a child, he was beaten and robbed by three Romani boys. On the other hand, most of the violence he has encountered was caused by white people. This part of the first supervision session informed both Roman and Olga of their attitudes and cultural beliefs concerning Aleš's background.

Then Roman asked Olga about her opinion of familial influences on Aleš's attitudes. Olga especially notices that Aleš tries hard, as he probably has all his life. Nevertheless, it is obvious that his education has put him outside the Romani community, and he has failed to join the white community. But Olga is very impressed by his efforts, since she has also tried hard all of her life, and 
Aleš had to work under much more difficult conditions than she did.

It is apparent even in the beginning of the supervisory relationship that the supervisor has a responsibility to stress the role of self-reflection and set an example to the supervisee. The importance of self-reflection may be emphasized during the establishment of the supervisory contract when discussing the supervisee's motivation and expectations. Later, regular everyday elaboration is needed $^{47}$.

Watkins ${ }^{56}$ pointed out that the more experienced the supervisor is, the more self-reflection is used, with the supervisor's own experiences disclosed during supervision. Similarly, according to Dunne ${ }^{57}$, if supervisees are to learn to self-reflect well, the supervisor must also perform self-reflection. This model is crucial for supervisees' training ${ }^{47}$. Thus, supervisors who fail in self-reflection, in particular in multicultural orientation, also fail to explain to supervisees how cultural, racial, and ethnic identity affects the therapeutic and supervisory relationships ${ }^{26}$. Understanding the cultural, social, political, ethnic, and personal history of the supervisee before supervision is initiated aids the supervisor in structuring the supervision environment much better, for better communication of positive aspects and stimulation of personal growth. According to the current transcultural theory in counselling, individuals with various cultural background may perceive the supervisor's signs of confidence and strength differently ${ }^{58}$. Persons from certain cultural groups may prefer a directive supervisory approach, while others may prefer a more liberal and individual approach ${ }^{59}$. Moreover, supervisors must be aware of the fact that cultural background may be associated with different vulnerability and various styles of self-disclosure. Supervisors also need to consider their own cultural identity and its impact on what, as a result, they pay more or, conversely, less attention to $^{60}$.

\section{CONCLUSIONS}

Strengthening reflectiveness in supervisees is a valuable way of improving the development of clinical skills as well as of helping them to continue their professional growth throughout all stages of their career ${ }^{61,62}$. Training and supervision focused on self-reflection are beneficial to both supervisees and their clients.

\section{REFERENCES}

1. Boud D, Keogh HR, Walker D (Eds). Reflection: Turning experience into learning. London: Kogan Page 1985.

2. Goleman D Emotional Intelligence. Bantam Books, New York 1995.

3. Wells A. Cognitive Therapy of Anxiety Disorders: A Practice Manual and Conceptual Guide. Willey, Chichester 1997.

4. Kimmerling $R$, Zeiss $A$, Zeiss $R$. Therapist emotional responses to patients: Building a learning-based language. Cogn Behav Pract 2000;7:312-21.

5. Kolp DA. Experiential learning. Englewood Cliffs, NJ: Prentice Hall, 1984.
6. Schon D. Educating the Reflective Practitioner. San Francisco, CA: Jossey-Bass 1987.

7. Beck AT, Freeman A, Davis DD (eds). Cognitive Therapy of Personality Disorder. The Guilford Press, New York, 2004.

8. Thwaites R, Bennett-Levy J. Conceptualizing Empathy in Cognitive Behaviour Therapy: Making the Implicit Explicit. Behavioural and Cognitive Psychotherapy 2007;35:591-612.

9. Hoffart A, Versland S, Sexton H. Self-understanding, empathy, guided discovery, and schema belief in schema-focused cognitive therapy of personality problems: a process-outcome study. Cognitive Therapy and Research 2002;26:199-219.

10. Gilbert P, Leahy RL: The Therapeutic Relationship in CognitiveBehavioral Therapy. London, England: Routledge-Brunner 2007.

11. Hardy G, Cahill J, Barkham M. Active ingredients of the therapeutic relationship that promote client change: a research perspective. In: Gilbert P and Leahy RL (Eds.), The Therapeutic Relationship in the Cognitive-Behavioural Psychotherapies. London: Routledge 2007;24-42.

12. Greenberg LS. Emotion in the relationship in emotion focused therapy. In: Gilbert P and Leahy RL (Eds.), The Therapeutic Relationship in the Cognitive-Behavioural Psychotherapies (43-62). London: Routledge, 2007.

13. Praško J, Vyskočilová J, Šlepecký M, Novotný M. Principles of supervision in cognitive behavioural therapy. Biomed Pap Med Fac Univ Palacky Olomouc Czech Repub 2011;155:XX. epub ahead of print. doi: 10.5507/bp.2011.022.

14. Bennett-Levy J. Therapist skills: a cognitive model of their acquisition and refinement. Behavioural and Cognitive Psychotherapy 2006;34:57-78.

15. Kuyken W, Padesky CA, Dudley R.. Collaborative Case Conceptualization: working effectively with clients in cognitivebehavioural therapy. New York: Guilford 2009.

16. Anderson JR, Bothell D, Byrne MD, Douglass S, Lebiere C, Qin Y. An integrated theory of mind. Psychological Review 2004;111:1036-60.

17. Bennett-Levy J, McManus F, Westling BE, Fennell M. Acquiring and Refining CBT Skills and Competencies: Which Training Methods are Perceived to be Most Effective? Behavioural and Cognitive Psychotherapy, 2009;37:571-83.

18. Skovholt TM, Ronnestad MH. The Evolving Professional Self: Stages and Themes in Therapist and Counselor Development. New York, NY: Wiley 1992.

19. Leahy RL. Overcoming Resistance in Cognitive Therapy. The Guilford Press, New York 2003.

20. Orchowski L, Evangelista NM, Probst DR. Enhancing supervisee reflectivity in clinical supervision. A case study illustration. Psychotherapy Theory Research Practice Training 2010;47:51-67.

21. Hoffart A, Hedley LM, Thornes K, Larsen SM, Friis S. Therapists' emotional reactions to patients as a mediator in cognitive behavioural treatment of panic disorder with agoraphobia. Cogn Behav Ther 2006;35(3):174-82.

22. Jennings $L$, Skovholt TM. The cognitive, emotional, and relational characteristics of master therapists. J Counseling Psychology 1999;46:3-11.

23. Rogers CR: On Becoming a Person: A Therapist's View of Psychotherapy. London: Constable and Company 1967.

24. Pope KS, Tabachnick BG, Keith-Spiegel P. Ethics of practice: The beliefs and behaviors of psychologists as therapists. American Psychologist 1987;42:992-1006.

25. Vasquez MJT. Psychologist as clinical supervisor: Promoting ethical practice. Professional Psychology: Research and Practice 1992;23:196-202.

26. Ramirez M. Multicultural Psychotherapy: An Approach to Individual and Cultural Differences. Boston, MA: Allyn \& Bacon 1999.

27. McGlinn JM. The impact of experiential learning on student teachers. Experiential Learning 2003;76:143-7.

28. Mueller A. Looking back and looking forward: Always becoming a teacher educator through self-study. Reflective Practice 2003;4:6784.

29. McAlpine L Weston C, Beauchamp J, Wiseman C, Beauchamp C. Building a metacognitive model of reflection. Higher Education 1999;37:105-31.

30. Lyon PM, Brew A. Reflection on learning in the operating theatre. Reflective Practice 2003;4:53-66. 
31. Billings $D$, Kowalski K. Journaling: A strategy for developing reflective practitioners. J Continuing Education Nurs 2006;37:104-5.

32. Kerry S. Facilitating supervisory relationships: The role of the supervisor. Crossing Boundaries: An Interdisciplinary Journal 2006;1:53-67.

33. Ward CC, House RM. Counseling supervision: A reflective model. Counselor Education Supervision 1998;38:32-3.

34. Safran JD, Muran JC. Negotiating the Therapeutic Alliance: a relational treatment guide. New York: Guilford; 2000.

35. Bennett-Levy J, Lee N, Travers K, Pohlman S, Hamernik E. Cognitive therapy from the inside: enhancing therapist skills through practising what we preach. Behavioural and Cognitive Psychotherapy 2003;31:145-63.

36. Brown KW, Ryan RR. The benefits of being present: Mindfulness and its role in psychological well-being. J Person Social Psychology 2003;84:822-48.

37. Machado PPP, Beutler LE, Greenberg LS. Emotional recognition in psychotherapy: impact of therapist level of experience and emotional awareness. Journal of Clinical Psychology 1999;55:39-57.

38. Milne D. CBT supervision: from reflexivity to specialization. Behavioural and Cognitive Psychotherapy 2008;36:779-86.

39. Laireiter AR, Willutzki U. Self-reflection and self-practice in training of cognitive behaviour therapy: an overview. Clinical Psychology and Psychotherapy 2003:10:19-30.

40. Baum BE, Gray JJ. Expert modeling, self-observation using videotape, and acquisition of basic therapy skills. Professional Psychology: Research and Practice 1992;23:220-5.

41. Hawkins P, Shohet R. Supervision in the Helping Professions. Open University Press, Buckingham 2000.

42. Prasko J, Vyskocilova J. Countertransference during supervision in cognitive behavioral therapy. Activitas Nervosa Superior Rediviva 2010b;52:251-60.

43. Prasko J, Diveky T, Grambal A, Kamaradova D, Mozny P, Sigmundova Z, Slepecky M, Vyskocilova J. Transference and counter-transference in cognitive behavioral therapy. Biomed Pap Med Fac Univ Palacky Olomouc Czech Repub 2010:154:189-98.

44. Young, JE, Klosko JS, Weishaar ME. Schema Therapy: a practitioner's guide. New York: Guilford, 2003.

45. Prasko J, Diveky T, Mozny P, Sigmundova Z. Therapeutic letters changing the emotional schemas using writing letters to significant caregivers. Act Nerv Super Rediviva 2009;51:163-7.

46. Sutton $L$, Townend $M$, Wright J. The experiences of reflective learning journals by cognitive behavioural psychotherapy students. Reflective Practice 2007:8:387-404.

47. Bernard JM, Goodyear RK: Fundamental of Clinical Supervision (3rd ed.). Boston MA: Pearson 2004
48. Overholser JC. The Socratic method as a technique in psychotherapy supervision,. Professional Psychology: Research and Practice 1991;22:68-74.

49. Beck JS, Sarnat JE, Barenstein V. Psychotherapy-based approaches to supervision. In: Falender CA, Shafranske EP (eds): Casebook for Clinical Supervision. American Psychiatric Association, Washington 2008;57-96

50. Skovholt TM, Ronnestad MH: (2001). The long, textured path from novice to senior practitioner. In: Skovholt TM (Ed.), The Resilient Practitioner: Burnout Prevention and Self-care Strategies for Counselors, Therapists, Teachers, and Health Professionals. Boston: Allyn and Bacon 2001;25-54.

51. Linehan MM, McGhee DE. A cognitive-behavioral model of supervision with individual and group component. In: Greben SE and Ruskin R (eds): Clinical Perspectives on Psychotherapy Supervision. American Psychiatric Press, Inc. Washington DC 1994;165-88.

52. Kadushin A. Supervision in Social Work. New York, NY: Columbia University Press, 1976.

53. Powers DJ. Games counselors plays in supervision. Professional Counselor 1989;32-4.

54. Bennett-Levy J, Beedie A. The ups and downs of cognitive therapy training: What happens to trainees' perception of their competence during a cognitive therapy training course? Behavioural and Cognitive Psychotherapy 2007;35:61-75.

55. Hahn WK. The experience of shame in psychotherapy supervision. Psychotherapy 2001;38:272-82.

56. Watkins CE. Psychotherapy supervisor and supervisee: Developmental models and research nine years later. Clinical Psychology Review 1995;15:647-80.

57. Dunne RV. The acquisition of professional activity in teaching. In: Harvard G \& Hodkinson P (eds): Action and reflection in teacher education. Norwood, NJ: Ablex 1994;105-24.

58. Cook DA, Helms JE. Visible racial/ethnic group supervisees' satisfaction with cross-cultural supervision as predicted by relationship characteristics. J Counseling Psychology 1988;25:268-74.

59. Gardner LH. Racial, ethnic, and social class considerations in psychotherapy supervision. In: Hess AK (ed.): Psychotherapy Supervision: Theory, Research and Practice. New York, NY: Wiley 1980;474-508.

60. Serok S, Urda LV. Supervision in social work from a gestalt perspective. Clinic Supervisor 1987;5:69-85.

61. Havrdová Z: Competencies in social work [Kompetence v praxi sociální práce]: Praha: Osmium, 1999.

62. Havrdová Z: Many faces, one target. [Mnoho tvárii, jeden cíl]. In Havrdová Z, Hajný M et al.: Practical supervision [Praktická supervize]. Galén, Praha 2008; 47-64. 